\title{
Experimental investigation of optical snow properties
}

\author{
Claude Sergent, Evelyne Pougatch, Marcel Sudul \\ Météo-France, Centre National de Recherches Météorologiques, Centre d'Etudes de la Neige, 1441 rue de la Piscine, \\ 38406 Saint Martin d'Hères Cedex, France \\ BARBARA BOURDELlES \\ Laboratoire de Glaciologie et de Géophysique de l'Environnement du CNRS, B.P.96, \\ 38400 Saint Martin d'Hères Cedex, France
}

\begin{abstract}
The authors have developed an experimental device in a cold laboratory with the purpose of measuring optical parameters of natural snow depending on grain-size, impurity content and density. Snow samples were prepared from homogeneous layers in order to measure the radiative properties of clearly identified snow types. The first part of this paper describes the working assumptions and the experimental device. In the second part, experiment results are described and discussed. We have compared albedo measurements of different natural snow types with theoretical values derived from physical optics, based on Mie scattering. The albedo evolution of three different snow types submitted to temperaturegradient metamorphism is analyzed.
\end{abstract}

\section{INTRODUCTION}

Solar radiation is important and often the main energy source involved in the snow-energy balance. Therefore knowledge of interactions between radiation and snow is fundamental. The accurate determination of optical and physical parameters of different snow types is necessary to use in snow-cover modelling and consequently is an important parameter in the climate change scenario. Moreover, the relationship between grain-size, impurity content and spectral albedo of snow has to be known to improve remote-sensing techniques of snow cover.

At the snow-atmosphere interface, incident radiation is partly back-scattered and partly absorbed by snow. For the spectral range $\Delta \lambda$, if $F i_{\Delta \lambda}$ is the incident flux and $F r_{\Delta \lambda}$ is the back-scattered flux by snow, the spectral reflectance can be defined as:

$$
A_{\Delta \lambda}=\frac{F r_{\Delta \lambda}}{F i_{\Delta \lambda}} .
$$

$A_{\Delta \lambda}$ is an optical parameter of snow and it depends on wavelength, grain-size and impurity content, especially carbon-soot (Warren, 1984). Snow density has no direct effect on $A_{\Delta \lambda}$. Theoretical formulations exist which are based on different methods:

Two fluxes modeling deduced from tranfer equation (Dunkle and Bevans, 1956; Gidding and Lachapelle, 1961).

Physical modelling deduced from optical geometry (Bohren and Barkstrom, 1974).

Scattering of electromagnetic waves by short particules with Mie theory (Wiscombe and Warren, 1980).
In all the computations made with these methods, the snow representation is far from the reality. Wiscombe and Warren modelling is based on spherical ice grains, and so is quite in agreement with some real snow grains such as rounded grains, but not with other snow types. Moreover the grain bonds are not taken in account. Thus, experimental investigations on all types of snow are necessary to get accurate optical parameters values.

Literature on experimental data is in general not accurate for the following reasons:

accurate field measurements are very difficult to obtain;

snow-crystal types and sizes are usually described in a subjective and simplified manner;

impurity contents, especially carbon-soot, are rarely quantified (Mellor, 1965; O'Brien and Munis, 1975; Grenfell and Maykut, 1977; Kuhn and Sioga, 1978; Bolsenga, 1983).

To complete these data, we used from 1982 to 1985 an experimental device which measured extinction coefficients of natural snow according to the Bohren and Barkstrom formulation (Sergent and others, 1987). This device was not accurate for spectral albedo measurements, and therefore, since 1986, in connection with works concerning physical snow cover model CROCUS (Brun and others, 1989), we have developed a second experimental device which allows us to measure spectral albedo and extinction coefficient with 10 nanometers spectral resolution on the $400-1000 \mathrm{~nm}$ band.

These investigations were principally conducted during the $1989 / 90$ and $1990 / 91$ winters on natural snow collected at different locations of the Alps in 
Grenoble area. Some experiments used snow directly collected from snow-pack layers; others used snow samples submitted to controlled metamorphism in a cold laboratory.

\section{EXPERIMENTAL DEVICE}

As a working assumption we considered snow as a semiinfinite medium, and we studied the interaction between snow and radiation under diffuse illumination. The physical part of the device was placed in a cold laboratory. The measurement devices were set outside the cold room in order to protect electronic components from low temperatures. Furthermore, snow-crystal types of each snow sample were identified, and an original method was used to determine an objective factor size. The density and carbon-soot contents of snow were also measured.

Experiments were conducted in a cold room at a temperature of about $-10^{\circ} \mathrm{C}$. Diffuse illumination was obtained from a quartz tungsten halogen lamp of $250 \mathrm{~W}$ mounted in an aperture of an integrating sphere of $762 \mathrm{~mm}$ diameter. The inner sphere surface was coated with an Eastman 6080 white reflectance coating which has an albedo of 0.995 in the spectral range $400-1000 \mathrm{~nm}$. The light emitted by the lamp undergoes multiple backscattering in the inner sphere surface, resulting in a diffuse illumination. The snow samples were placed at a $90^{\circ}$ angle to the light source in an aperture of $152 \mathrm{~mm}$ diameter.

\section{MEASUREMENTS}

A lens mounted in a collimating beam probe and facing the snow sample was set on the integrating sphere. It collected light back-scattered by the snow sample (theoretical acceptance angle of $8^{\circ}$ ). The flux was transmitted by an optic fibre $\left(6 \mathrm{~mm}\right.$ diameter and $60^{\circ}$ acceptance angle) outside the cold laboratory to a monochromator. In order to avoid direct illumination of the snow sample and lens by the light source, baffles were placed between the lamp and the apertures of the lens and the snow sample (Fig. 1a). To limit errors introduced by the uncertainty of the lens acceptance angle and by other components of the experimental device, we used calibration curves for the albedo measurements. They were deduced, for each $10 \mathrm{~nm}$ wavelength band, from the back-scattered flux measured on four diffuse reflectance standards of spectralon product. These values were $0.99,0.80,0.60$ and 0.40 for the spectral range investigated. For each curve the equation is:

$$
A_{x}=f\left(\frac{F r_{x}}{F r_{\mathrm{a}}}\right)
$$

$A_{x}$ is the albedo for a surface $\mathrm{x}, F r_{x}$ is the measured backscattered flux for a surface $x$, and $F r_{\mathrm{a}}$ is the measured back-scattered flux for the reflectance standard 0.99.

To get the albedo $A_{x}$ of a snow sample, back-scattered flux measurements of snow samples were made alternately with measurements of back-scattered fluxes by the reflectance standard 0.99 . This method was applied on
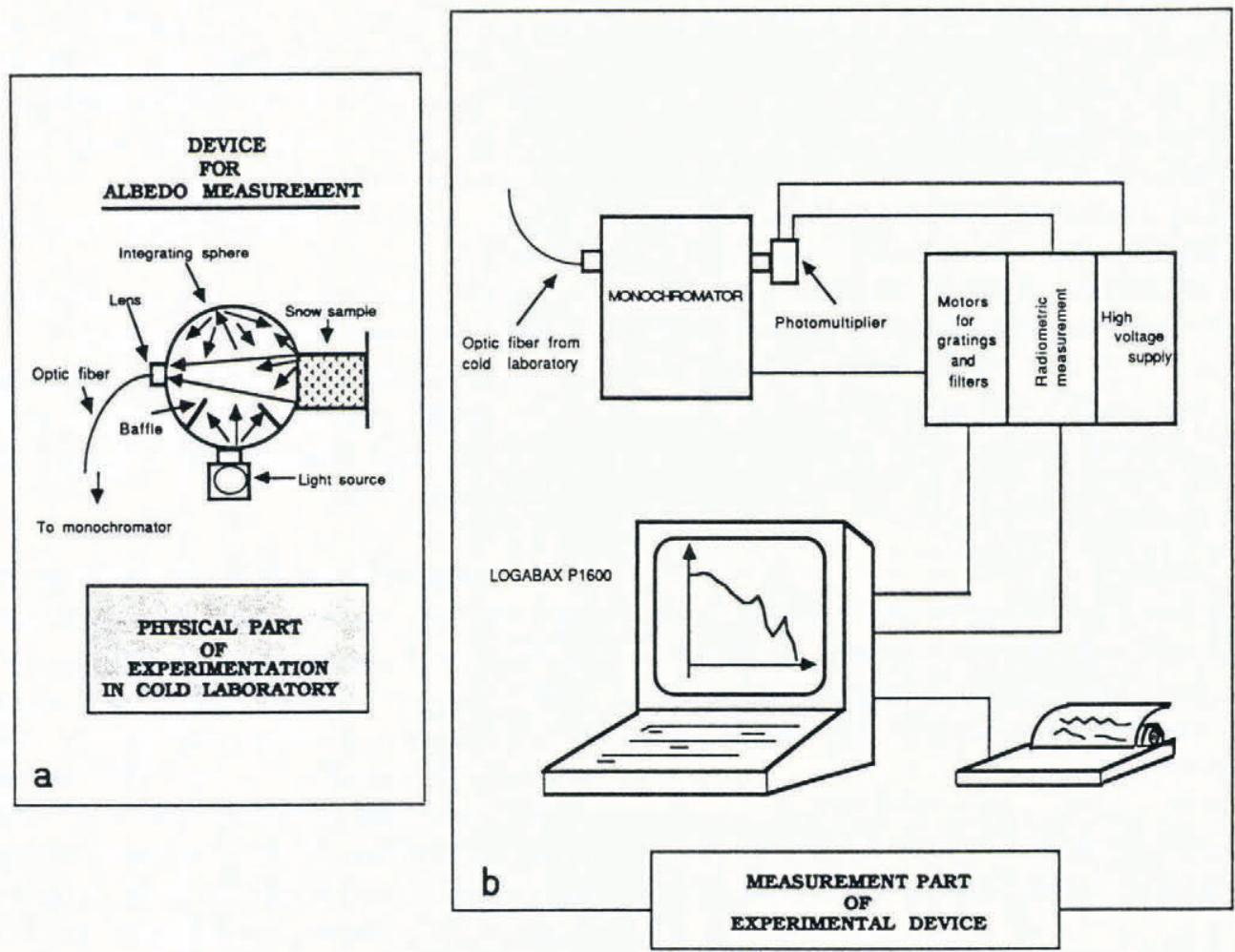

Fig. 1. Experimental device. (a) Upper view of apparatus located in the cold laboratory. (b) Apparatus located outside the cold laboratory. 

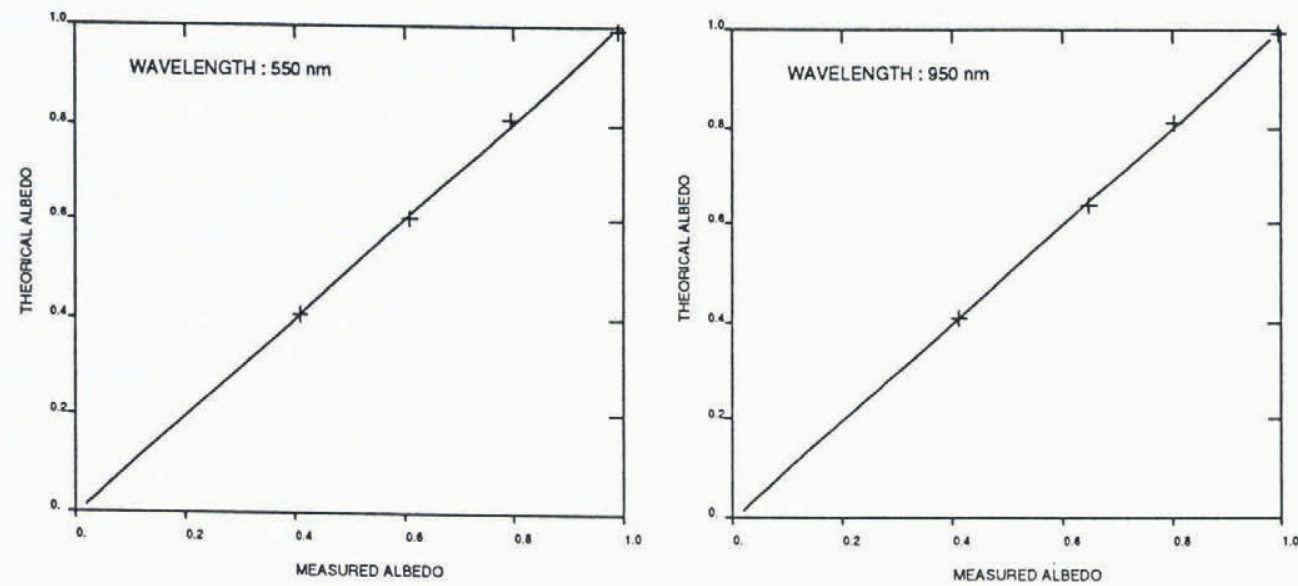

Fig. 2. Theoretical albedo of reflectance standards plotted against measured albedo for two wavelengths.

reflectance standards. It showed a variability less than $2 \%$ for measured albedos over the spectral range under investigation (Fig. 2).

The back-scattered flux from the snow samples was transmitted through the optic fibres outside the cold laboratory, which connected with a grating monochromator delivering output fluxes over $10 \mathrm{~nm}$ wavelength bands. These fluxes were then measured by a photomultiplier connected to a radiometric and high-voltage supply system. A micro-computer managed the step-bystep and filter motors of the monochromator, and the radiometric measurement system. Radiometric measurements were then recorded automatically (Fig. 1b).

\section{Sampling method}

Different natural snow types were collected during winter or spring. They were taken from homogeneous layers and brought back to the cold laboratory into large isotherm boxes. They were stocked at a temperature of about $20^{\circ} \mathrm{C}$ for many days without any damage. To measure their radiative properties, snow samples were placed into large cylindric samplers (152 mm diameter and $250 \mathrm{~mm}$ long), with the inner surface coated with a Duraflect product which has a reflectance of about 0.99 on the working spectral range. These features appear to be in quite good agreement with the semi-infinite assumption. The samplers were filled up by sifting snow through a screen of $4 \mathrm{~mm}$ mesh, assuring a random crystal orientation and a reasonable homogeneity of the snow density.

Some parts of the experimental device do not agree perfectly with theoretical assumption:

Incident light is not perfectly diffuse.

Samples have finite sizes and the inner surface of the samples have a high reflectance but not equal to 1 .

Subsequently, a part of the radiation is absorbed by the inner sides of the sampler so that an albedo underestimation can be expected.

\section{Physical characterization of snow}

Most authors do not specify how they measure grainsizes. For spherical ice crystals, Raymond and Tushima
(1979) observed that in saturated snow, the cumulative distribution of particule diameters had the same pattern with increasing time. Brun (1989), observed the same pattern for clusters of non-spherical grains. In this case, each grain which can be seen along the circumference of the cluster is considered as a single grain. With the assumption that this behaviour can be applied to other snow types, mean volume or mean diameter of a snow sample can be chosen as a representative size factor of a snow type. In our investigations, we used a pictureanalysis system developed in our laboratory. It computes the mean convex radius of curvature of randomly chosen clusters corresponding to a sample of about 60 or 80 different crystals. For each snow sample, we computed the mean convex radius as an objective snow-factor size. We attempted to get a relationship between the mean convex diameters and theoretical spherical grain diameters according to Wiscombe and Warren modeling. In this way, we used mean spectral values in the $980-1000 \mathrm{~nm}$ band. For this spectral range, reflectance only depends on the grain-size for carbon-soot content less than 1 ppmw (Wiscombe and Warren, 1980). The theoretical diameter

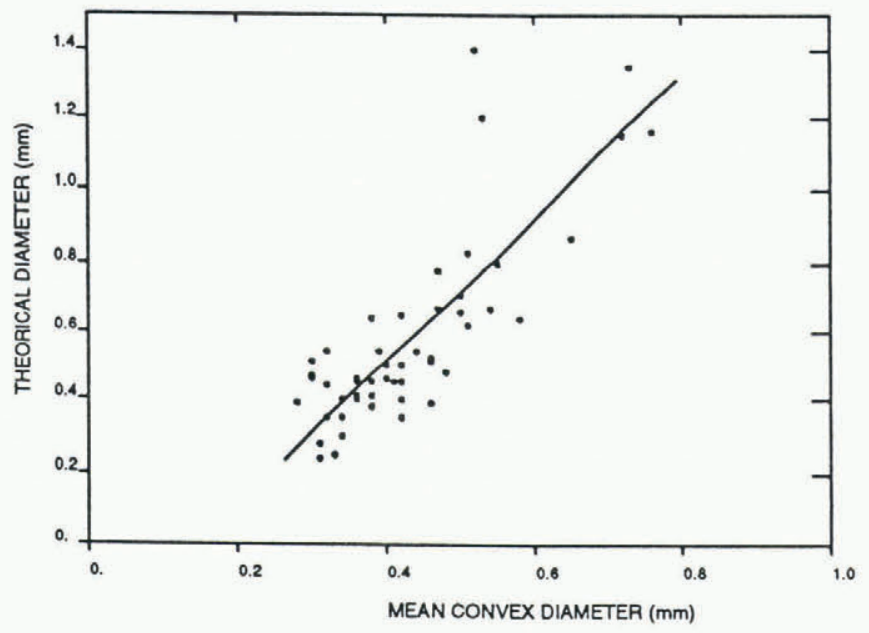

Fig. 3. Relationship between mean convex diameters and theoretical diameters derived with Wiscombe and Warren model. (Data of the whole experiments are plotted.) 
is defined as the diameter of the spherical grains which have an albedo value equal to the measured one for the 980-1000 nm band. In Figure 3, we have plotted theoretical diameter values against measured mean convex diameters. The relationship between the two parameters can be expressed as a polynomial regression of the second degree. From now, we deduce the theoretical diameter from the measured mean convex diameter according to this relationship. Each investigated snow sample was analysed in order to determine carbon-soot content which strongly alters optical parameters on the visible part of the spectrum (Warren, 1984). The analyses were made by Coulometric titration (Cachier, 1989).

\section{RESULTS}

Up to the present, about 70 snow samples have been investigated. We measured optical parameters values for different natural snow types collected in the field, and for different steps of metamorphism conducted in a cold laboratory.

\section{Albedo of different snow types}

The experimental albedo values of four different natural snow types are compared with theorical values derived with the Wiscombe and Warren model (Fig. 4). The grain-sizes of the four different snow types analyzed show distinct curves, especially in the near-infrared spectrum, but with the same shapes. Experimental and theoretical values are very close. But in the visible spectrum, the
Table 1. Physical features of the snow investigated in the first experiment (different snow types)

\begin{tabular}{cccc} 
Snow type & $\begin{array}{l}\text { Snow Mean convex } \\
\text { density diameter }\end{array}$ & $\begin{array}{c}\text { Theoretical } \\
\text { diameter }\end{array}$ & $\begin{array}{c}\text { Carbon-soot } \\
\text { content }\end{array}$ \\
$\mathrm{Mg} \mathrm{m}^{-3}$ & $\mathrm{~mm}$ & $\mathrm{~mm}$ & $\mathrm{ppmw}$ \\
\hline
\end{tabular}

$\begin{array}{lllll}\text { Fragmented } & 0.165 & 0.31 & 0.26 & 0.12\end{array}$

precipitated

particles and

stellar dendrites

\begin{tabular}{|c|c|c|c|}
\hline $\begin{array}{l}\text { Rounded } \\
\text { grains }\end{array}$ & 0.367 & 0.38 & 0.34 \\
\hline Depth hoar & 0.375 & 0.35 & 0.31 \\
\hline $\begin{array}{l}\text { Clustered } \\
\text { rounded } \\
\text { grains }\end{array}$ & 0.474 & 0.72 & 0.86 \\
\hline
\end{tabular}

* Theoretical diameter is deduced from the regression curve of Figure 2.

theoretical values are lower than the experimental ones for most of the snow samples investigated. This general behaviour is probably the consequence of the physical

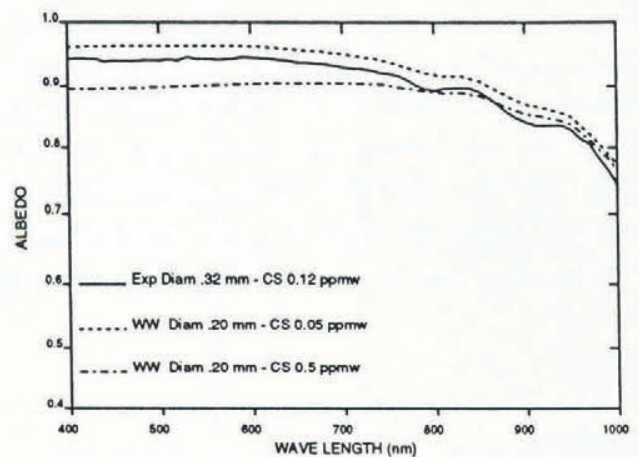

a

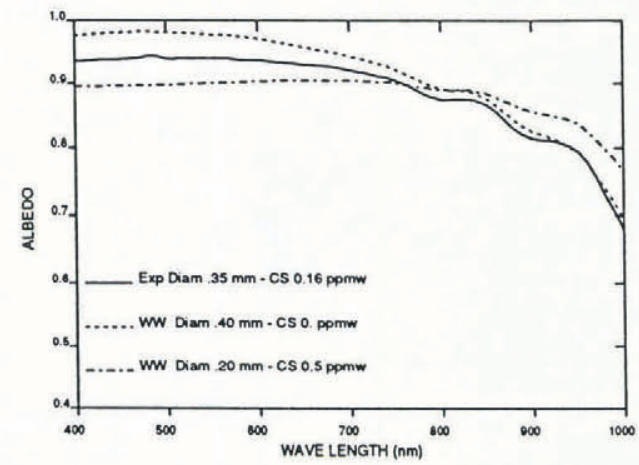

C

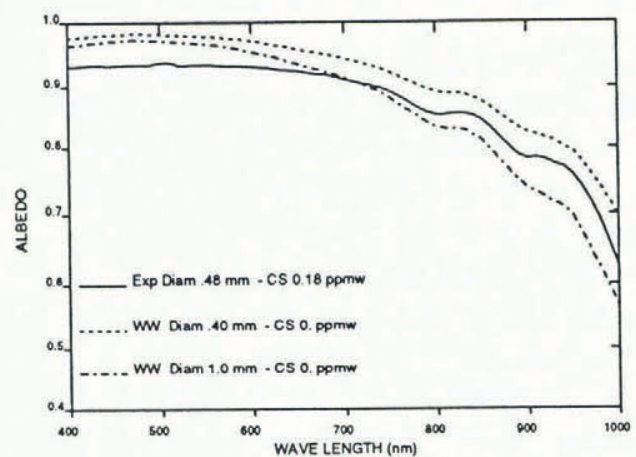

b

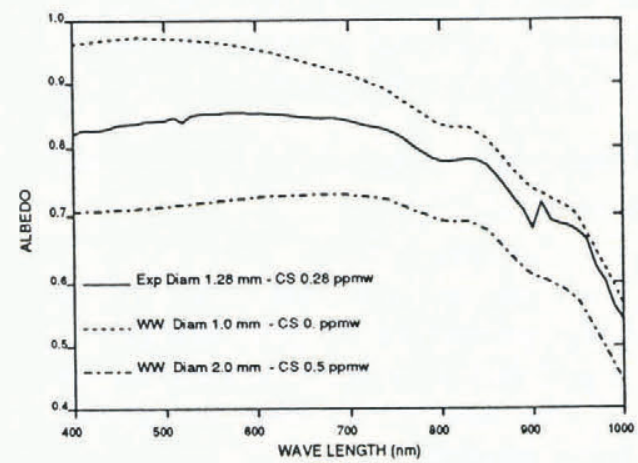

d

Fig. 4. Albedo curves of four different snow types (Exp.) compared with Wiscombe and Warren data modeling (WW). (a) Fragmented precipitation particles. (b) Rounded grains. (c) Depth hoar. (d) Clustered rounded grains. On each figure, in regard of the used lines, theoretical diameter ( $\mathrm{mm}$ ) and carbon-soot content (ppmw) are plotted. 


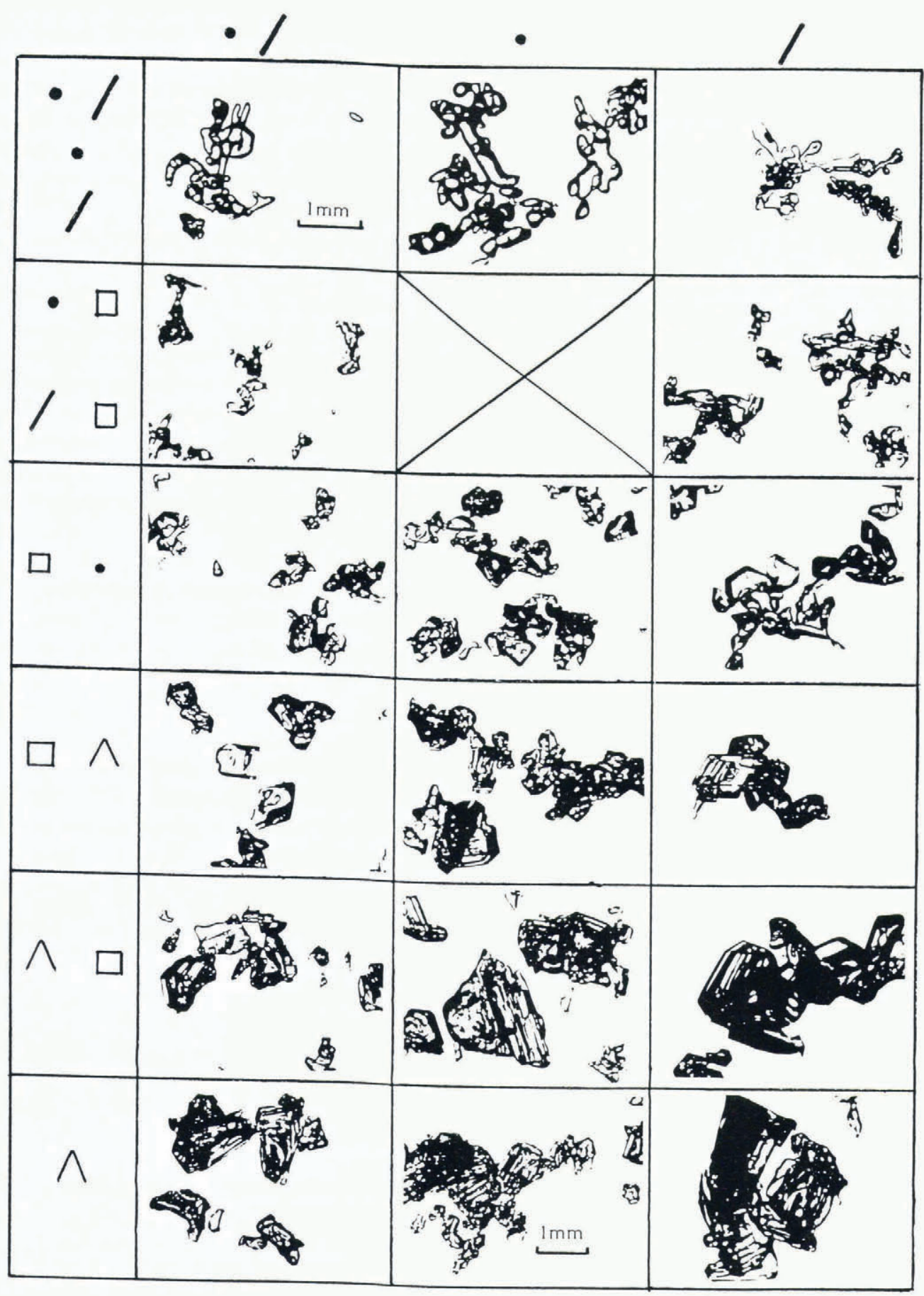

Fig. 5. Typical shapes of snow grains at the different metamorphism steps used on Figure $6 c$ and d. First column: rounded grains and fragmented precipitation particles. Second column: rounded grains. Third column: fragmented precipitation particles. General scale is noted on the upper left of the picture. Different scales are noted on the relevant photographs.

features of carbon-soot used in the model. The characteristics of the snow investigated appear in Table 1. The theoretical diameter deduced from the measured mean convex diameter allows a good agreement between the experimental results and the theoretical computations, so it can be used as an objective factor size.

\section{Temperature-gradient metamorphism}

Three different snow types were submitted to a high temperature-gradient metamorphism until they reached depth-hoar shape. Temperature-gradient was applied to large snow quantities, allowing snow samples to be taken at different metamorphism steps (Fig. 5). The evolution of snow was simulated by allowing a temperature gradient of about $50 \mathrm{deg} \mathrm{m}^{-1}$ according to a former experimental investigation on temperature-gradient effect (Marbouty, 1980). One of the most interesting aspects of this choice was to keep impurity content almost constant. In this case albedo, especially on the near-infrared band, depends on grain shape and grain-size. Table 2 summarizes physical features of the investigated snows. Figure $6 \mathrm{a}$ and $\mathrm{b}$ shows 
Table 2. Physical features of the investigated snow in the second experiment (temperature gradient)

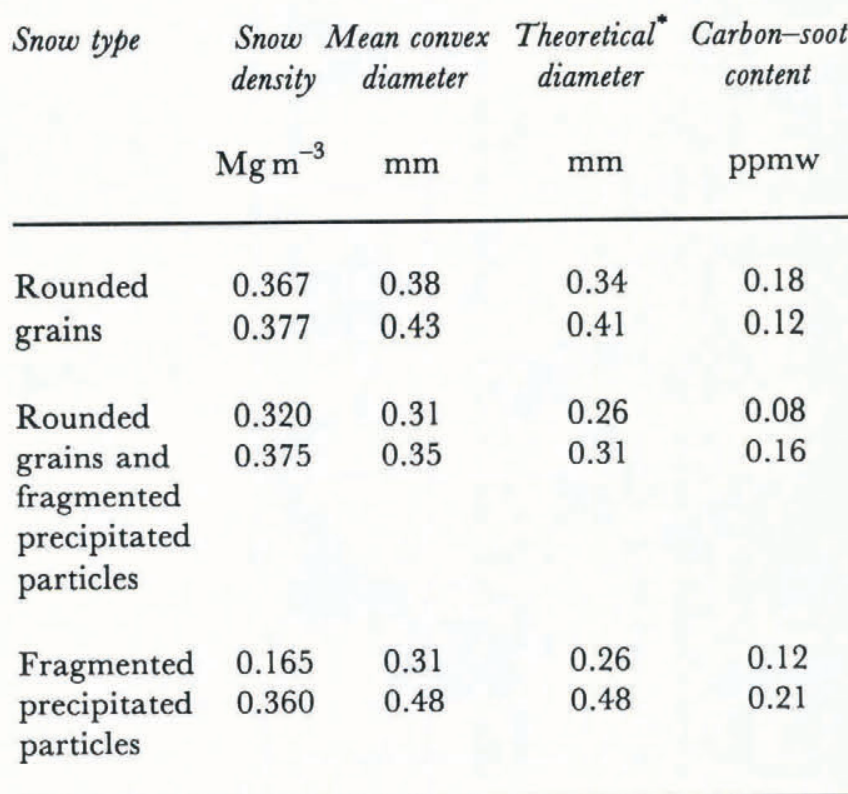

First data line is for the beginning of the experiment.

Second data line is for the end of experiment.

* The theoretical diameter is deduced from the regression curve of Figure 2. albedo curves at the beginning and end of the metamorphism. We observe in the visible part of the spectrum a high stability of albedo during the experiments. This confirms the stability of impurity content during the metamorphism and also that grain-size has a poor influence on albedo on the visible spectrum. On the near-infrared band, albedo decreased in the case of snow originally made of fragmented precipitation particles, while it increased in other cases where snow were made of rounded or rounded and fragmented precipitation particules. This behaviour corresponds to increasing and decreasing factor size. In Figure $6 c$ and $6 d$ we have plotted the mean albedo on visible $(540-560 \mathrm{~nm})$ and near-infrared $(980-1000 \mathrm{~nm})$ bands at different metamorphism steps. The experimental results show a decrease for the factor size of rounded grains. This can be explained by the appearance of angular shapes during the metamorphism. Fragmented precipitation particles are inversely losing their highly developed dendritic shapes, and this corresponds to a decrease in factor size. Considering the last step of the experiment made on the originally fragmented precipitation particles, it is obvious that albedo would be of about 0.66 for the $980-1000 \mathrm{~nm}$ band (Fig. 6d). This is confirmed by the corresponding albedo curve of Figure $6 \mathrm{~b}$, which shows an-abnormal behaviour on the $950-1000 \mathrm{~nm}$ band with an albedo greater than expected from the shape of the curve. The differences between near-infrared albedo correspond to significant different sizes of the depth-hoar grains. This can be explained by the density values at the begining of

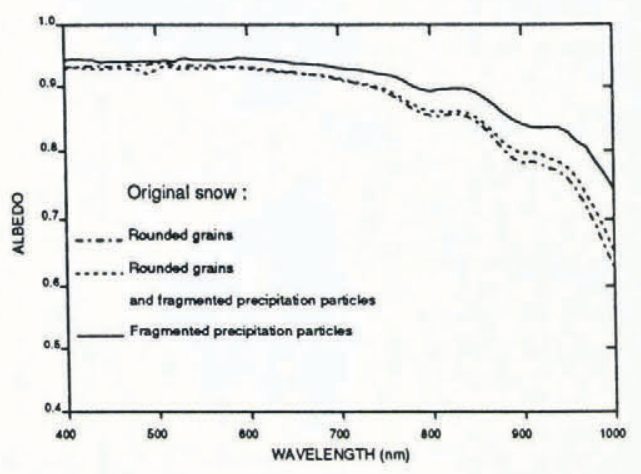

a

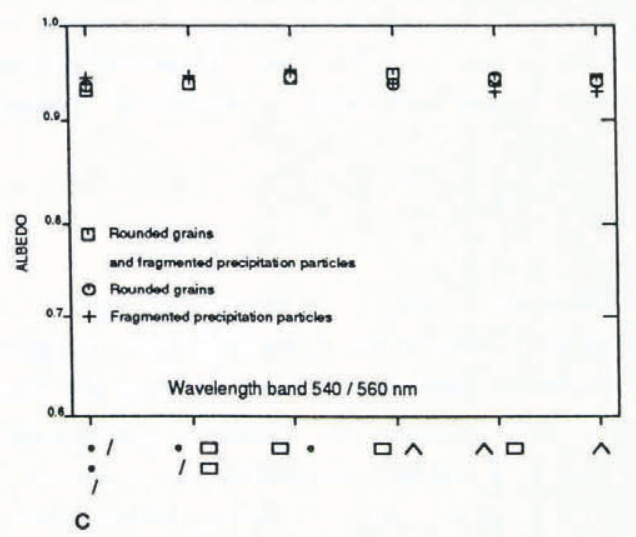

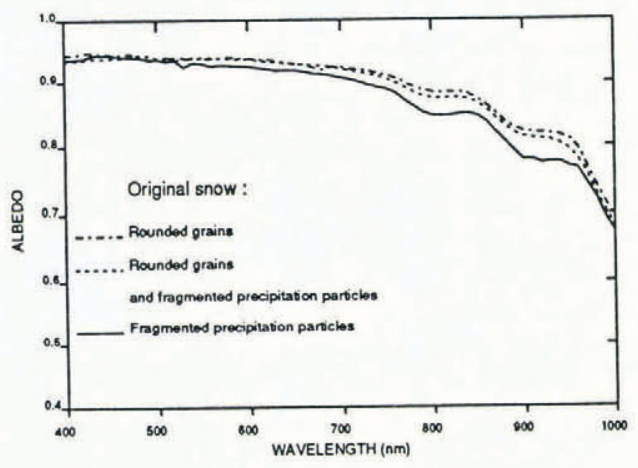

b

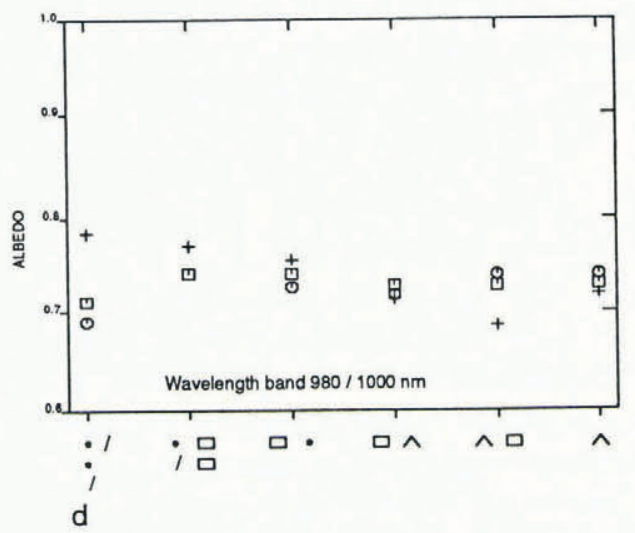

Fig. 6. Albedo behaviour during temperature-gradient metamorphism for three different original snow types. (a) Albedo curves of the three original snow types. (b) Albedo curves at the end of metamorphism. (c) and (d) Mean albedo values at different steps of metamorphism on visible and infrared part of the spectrum. 
metamorphism. The high density of rounded grains is certainly a limitation for depth-hoar growing (Marbouty, 1980).

\section{CONCLUSION}

The experimental method developed here is suitable for investigating the effect of the carbon-soot content and of the objective grain-size factor on the snow diffuse reflectance in the $400-1000 \mathrm{~nm}$ range. The relationship between mean convex diameters and size factors can be improved by a more advanced digital analysis system and by spectral reflectance measurements on the infrared spectral range beyond $1000 \mathrm{~nm}$. A better adjustment of carbon-soot physical features can improve the theoretical results of Wiscombe and Warren modelling. Nevertheless, the experimental albedo values obtained with our experimental device can already be used in physical models of snow cover and improve the remote-sensing techniques of snow cover.

\section{ACKNOWLEDGEMENTS}

Carbon-soot content analyses were conducted by $\mathrm{H}$. Cachier and J. Ducret of Centre des Faibles Radioactivites, Laboratoire mixte CNRS-CEA de Gif sur Yvette, France.

\section{REFERENCES}

Bohren, C. F. and B. R. Barkstrom. 1974. Theory of the optical properties of snow. F. Geophys. Res., 79(30), 4527-4535.

Bolsenga, S.J. 1983. Spectral reflectances of snow and fresh-water ice from 340 through $1100 \mathrm{~nm}$. F. Glaciol., 29(102), 296-305

Brun, E. 1989. Investigation on wet-snow metamorphism in respect of liquid-water content. Ann. Glaciol., 13, 2226.

Brun, E., E. Martin, V. Simon, C. Gendre and C.Coleou. 1989. An energy and mass model of snow cover suitable for operational avalanche forecasting. 7 . Glaciol., 35(121), 333-342.

Cachier, H., M. P. Bremond and P. Buat-Menard. 1989. Determination of atmospheric soot carbon with a simple thermal method. Tellus, 41B, 379-390.

Dunkle, R. V. and J.R. Bevans. 1956. An approximate analysis of the solar reflectance and transmittance of a snow cover. 7. Meteorol., 13(2), 212-216.

Giddings, J. C. and E. Lachapelle. 1961. Diffusion theory applied to radiant energy distribution and albedo of snow. F. Geophys. Res., 66(1), 181-189.

Grenfell, T.C. and G.A. Maykut. 1977. The optical properties of ice and snow in the Arctic Basin. 7. Glaciol., 18(80), 445-463.

Kuhn, M. and L. Siogas. 1978. Spectroscopic studies at McMurdo, South Pole and Siple stations during the austral summer 1977-78. Antarct. F. U.S., 13(4), 178179.

Marbouty, D. 1980. An experimental study of temperacure-gradient metamorphism. J. Glaciol., 26(94), 303312.

Mellor, M. 1965. Optical measurements on snow. CRREL Res. Rep. 169.

O'Brien, H. W. and R.H. Munis. 1975. Red and nearinfrared spectral reflectance of snow. CRREL Res. Rep. 332.

Raymond, C.F. and K. Tusima. 1979. Grain coarsening of water-saturated snow. F. Glaciol., 22(86), 83-105.

Sergent, C., P. Chevrand, J. Lafeuille and D. Marbouty. 1987. Caractérisation optique de différents types de neige. Extinction de la lumière dans la neige. $\mathcal{F}$. Phys. (Paris), 48, Colloq. C1, 361-367. (Supplément au 3.)

Warren, S. G. 1984. Impurities in snow: effects on albedo and snow-melt. (Review.) Ann. Glaciol., 5, 177-179.

Warren, S. G. and W.J. Wiscombe. 1980. A model for the spectral albedo of snow. II. Snow containing atmospheric aerosols. F. Atmos. Sci., 37(12), 2734-2745.

Wiscombe, W.J. and S. G. Warren. 1980. A model for the spectral albedo of snow. I. Pure snow. F. Atmos. Sci., 37(12), 2712-2733.

The accuracy of references in the text and in this list is the responsibility of the authors, to whom queries should be addressed. 